\section{New Sensations with Latest Implant Generations Allowing High Performance Strategies in Oral Implantology}

\section{Abstract}

In daily practice, we are constantly faced with the dilemma of choosing the right strategy between a conservative treatment and a "radical" one which includes extracting the tooth and replacing it with an implant... With or without setting an immediate esthetic fixed temporary prosthesis. Considering the psychological makeup of the patient (and of the practitioner!) and the real life experience of the 2 protagonists, critical situations are frequent where we must carefully weigh the pros and the cons of the various possible treatments. Latest implant generations - especially spiral implants - contribute to greater stability in poor quality bone sites, but also to improve implant placement even under precarious circumstances providing us - as practitioners and as patients as well - increased secure-pleasurable sensations while driving the implant treatments. Based on experience and advanced implant technology, this paper illustrates this purpose with a series of several case reports, challenging immediate implant placements in the esthetic zone in part 1 , and full arches replacements in part 2.

Keywords: Immediate implant; Single tooth replacement; Full arch replacement; Implant strategy; Esthetic zone; Spiral implants; Implant challenges

\author{
Michel Abbou \\ Dental Practice Paris, Champs-Elysées -26, \\ rue Marbeuf-75008, Paris, France
}

Vol. 2 No. 3: 17

\section{Corresponding author: Michel Abbou}

झ drmichel.abbou@wanadoo.fr

Dental Practice Paris, Champs-Elysées -26, rue Marbeuf-75008, Paris, France.

Tel: +33495450000

Citation: Abbou M. New Sensations with Latest Implant Generations Allowing High Performance Strategies in Oral Implantology. Periodon Prosthodon. 2016, 2:3.

Received: September 15, 2016; Accepted: September 28, 2016; Published: September 30, 2016

\section{Introduction}

There have been many changes in our therapeutic attitude since the Swedish school published its works concerning osseointegrated implants in 1985 [1]. Some of us, as practitioners, understood the revolution that was brought about by this new implant concept; others preferred to "wait and see" ... [2].

I personally was happy to be "at the right time, at the right place, in France", taking part in the birth of the first Department of Implantology in Paris-France (University Paris VII - 1986), standing behind and supporting our department head, Pr. Patrick MISSIKA. We were proud and very enthusiastic about how we were able to improve our patients' smiles and chewing function by following Branemark's procedures... while at the same time, trying to stretch and expand the strict boundaries recommended by the Swedish professor.

\section{Part I: Immediate Implant Placement in the Esthetic Zone}

As a result, starting in 1987, we began adopting protocols of immediate implant placement following tooth extraction [3-6] that was sanctioned by some authors $[7,8]$, but not allowed by Branemark and Co.; the reason being that the practitioner should only work "on healed and healthy bone site receivers". At that time, we were castigated by the orthodox Branemark followers in both France and abroad. But as time went by, the validity of our method was finally recognized [9] because of the satisfactory results [10-12].

During this same time period, other pioneering clinicians tried and sanctioned other protocols:

- One stage surgery [13-16];

- Immediate esthetic provisional crowns on single implants $[17,18]$; 
- Immediate fixed full-arch provisional prosthesis just after implant placements $[19,20]$.

These clinical protocols were, and still are, backed by research studies and clinical publications, along with implant shape evolution which enhance primary stability, osseous integration and stress-impact diminution while implants become functional [21-24].

As is evident from this technical feature, one point appears clear: nowadays, most of the implant systems use either conical or cylinder-conical shapes because it is undeniable that they improve implant stability $[25,26]$ which in turn leads to rapid osseointegration [27].

Furthermore, spiral implants have been shown to not only contribute to greater stability in poor quality bone sites, but also to improve implant placement even under precarious circumstances such as when doing immediate implant placement after tooth extraction [28-31].

The AlphaBio-Tec Implant System (SPI/ICE/NICE and recently available NEO) and NOBELBIOCARE Implant System (NOBELACTIVE) are recognized to be the leaders in that area. The purpose of this article, on the one hand, is to highlight the latest clinical as well as technological developments while also taking into consideration the demands of patients and treatment plans of the practitioner.

\section{Immediate implant placement in the esthetic}

\section{zone}

Until today, when confronted with the challenge of replacing an anterior compromised natural tooth, we usually choose from several specific implant designs and protocols [3,18,32-36]. It has become a quasi-routine, 1-hour procedure, often ending in placing an esthetic, temporary implant-supported crown onto the site. Then, after a period of 3 to 4 months, and after successful tissue integration, a permanent ceramic crown replaces the temporary one [36]. But the way of dealing with the clinical procedure can change with regard to:

- Clinical and Radiological (3D) tissue-site evaluation before tooth extraction;

- Anatomic parameters (proximal teeth and nasal or sinus fosses);

- Experience and self-confidence of the practitioner and his/ her team;

- Available implant systems;

- Patient motivation and those implications in the treatment. In cases where the anatomic context is not in optimal condition, but the patient's demands are still high, the clinician must take full advantage of high tech equipment which allows him/ her to follow a specific treatment plan that was developed and sanctioned after using a precise 3D X-ray analysis as well. Full cooperation from both the patient and the implant team are essential $[35,36]$.

Figures of cases 1 and 2 illustrate these kinds of challenges.

Case 1: December, 2009: young lady, 27 years old, presenting 2 mobile milk canines surmounted by 2 horizontally impacted permanent canines. She is in demand of a quick-efficient solution (Figures 1a-1x).

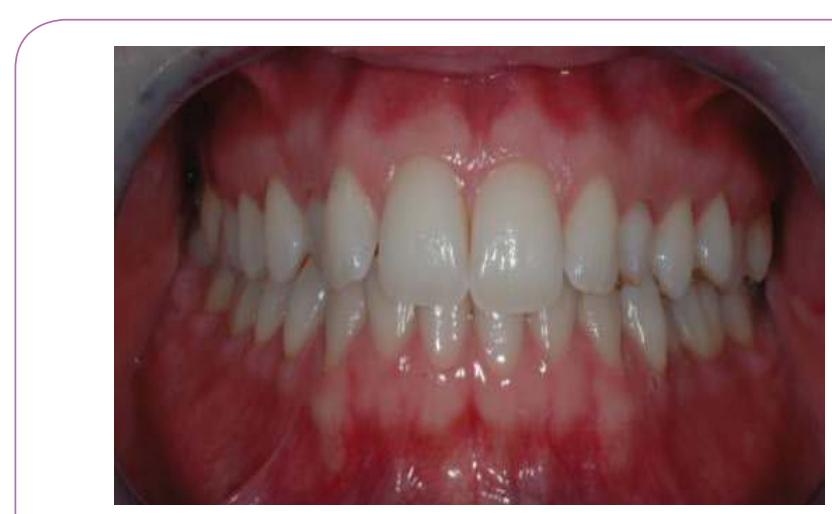

Figure 1a Initial clinical and radiological situation.

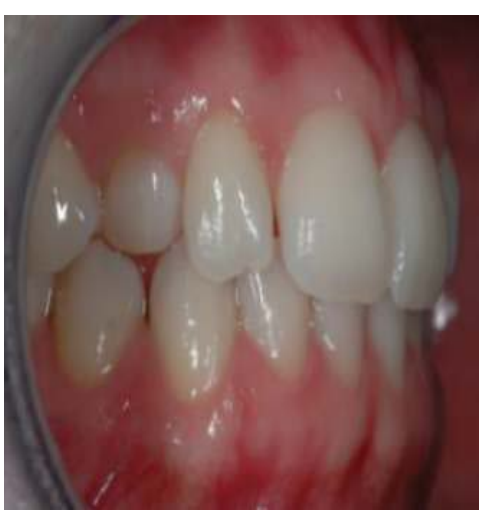

Figure 1b Initial clinical and radiological situation.

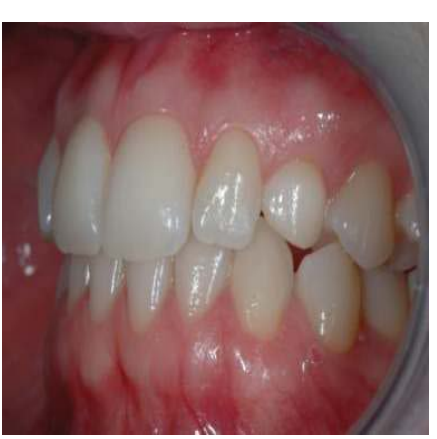

Figure 1c Initial clinical and radiological situation. 

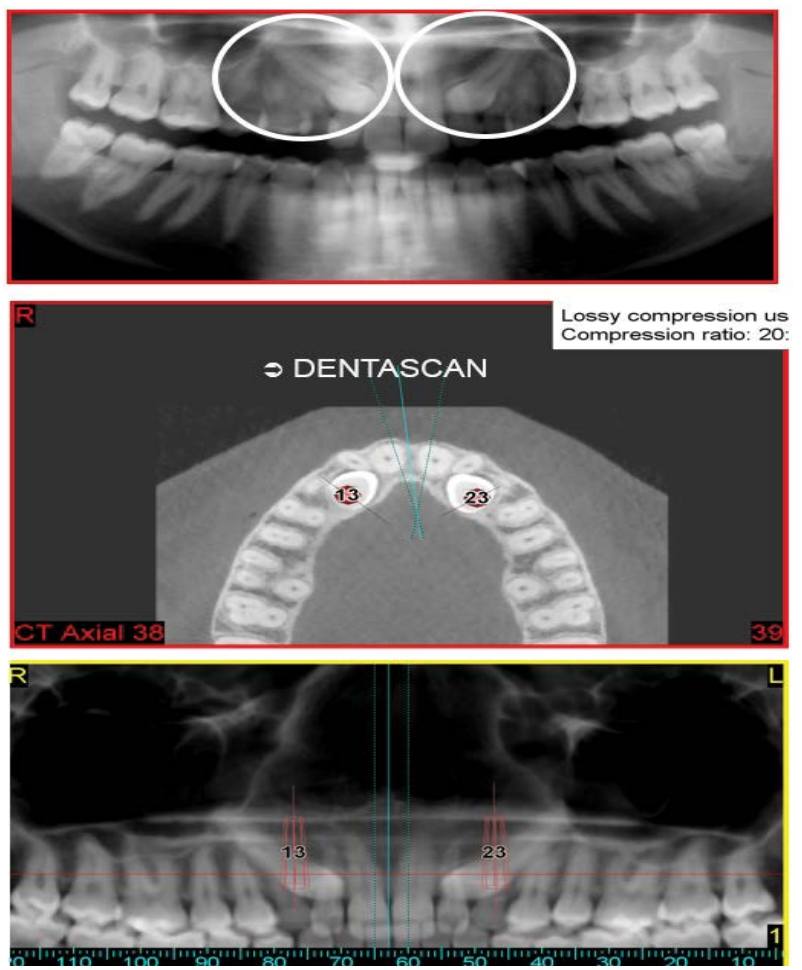

Figure 1d Initial clinical and radiological situation.

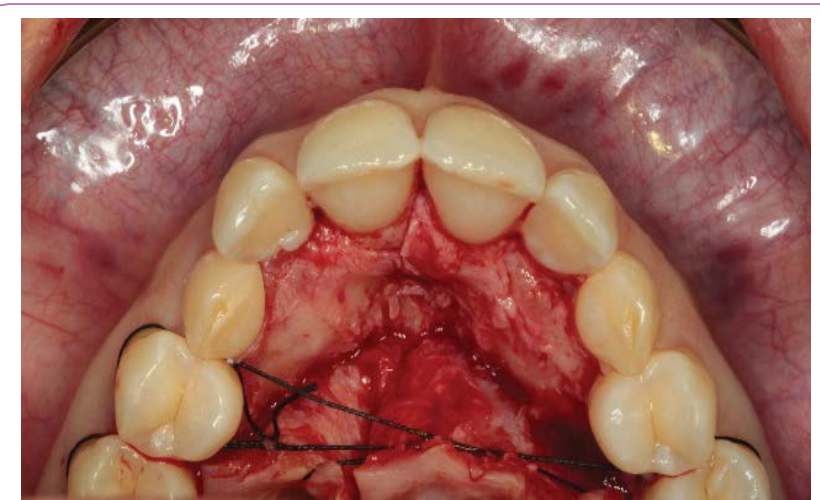

Figure 1e Teeth-extraction surgery.

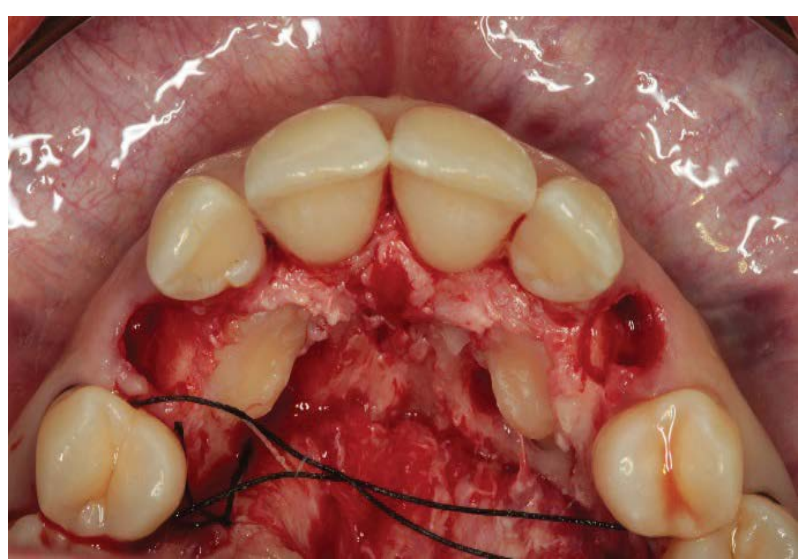

Figure 1f Teeth-extraction surgery.

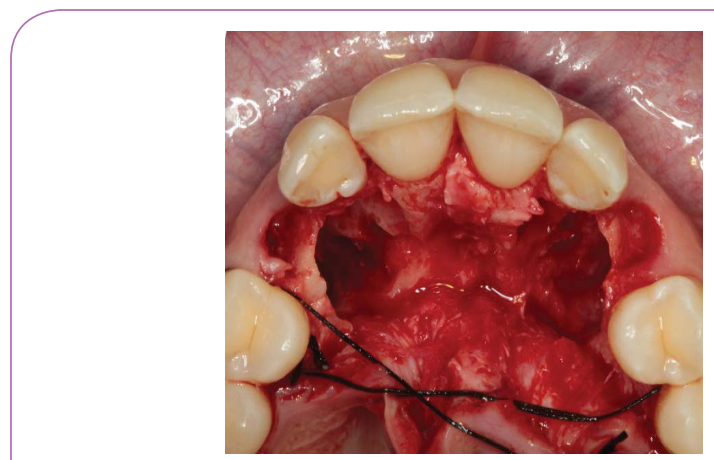

Figure 1g Teeth-extraction surgery.

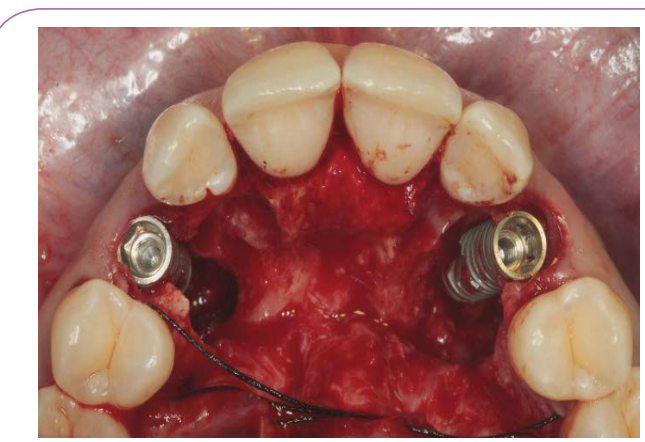

Figure 1h Implant placements (Nobel Active), despite precarious bone condition.

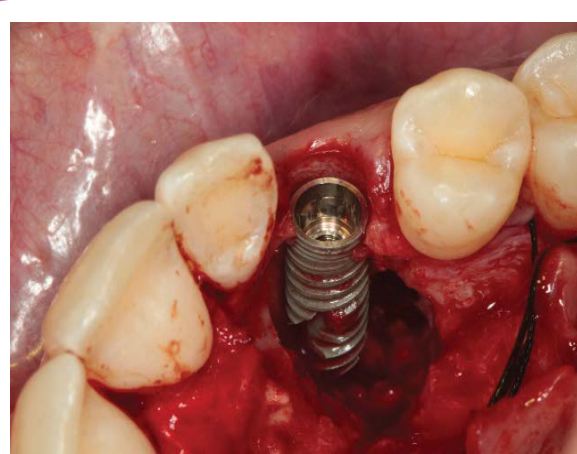

Figure 1i Implant placements (Nobel Active), despite precarious bone condition.

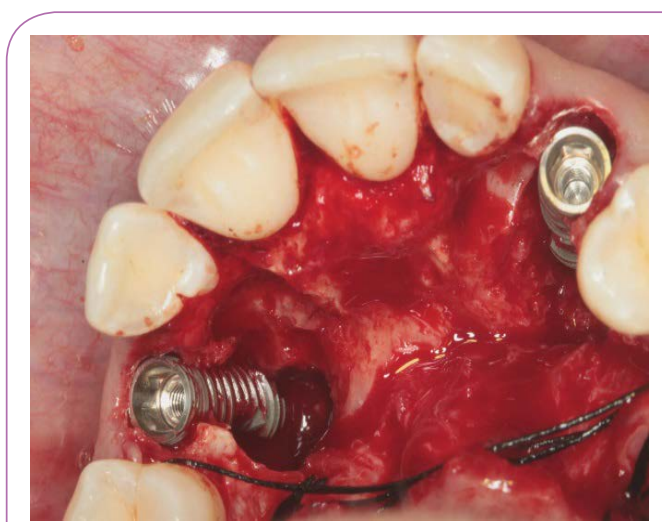

Figure 1j Implant placements (Nobel Active), despite precarious bone condition. 


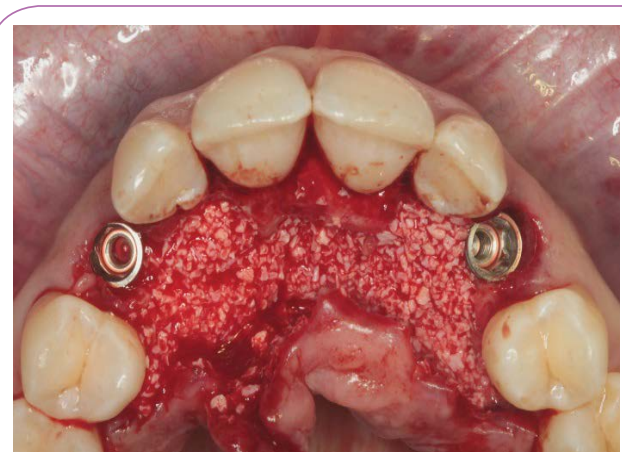

Figure 1k Bone-defects filling (Bio-Oss Geistlich) and gingival flap closure.

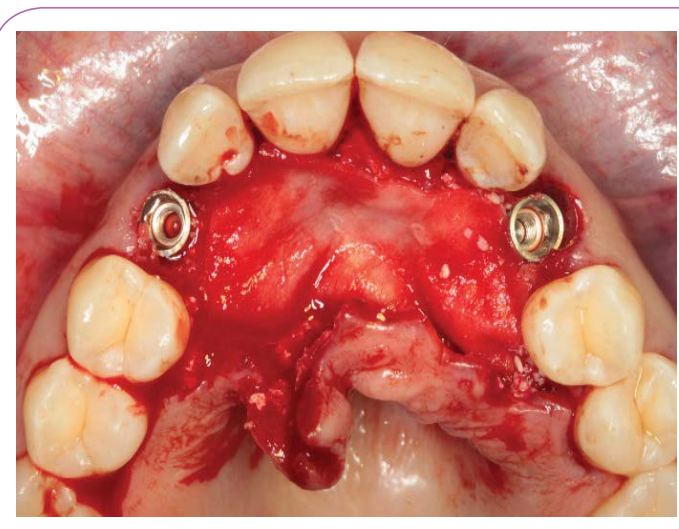

Figure 1l Bone-defects filling (Bio-Oss Geistlich) and gingival flap closure.

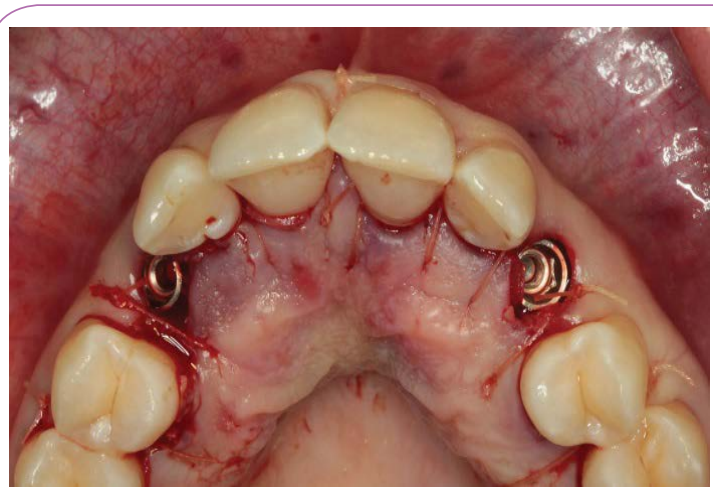

Figure 1m Bone-defects filling (Bio-Oss Geistlich) and gingival flap closure.

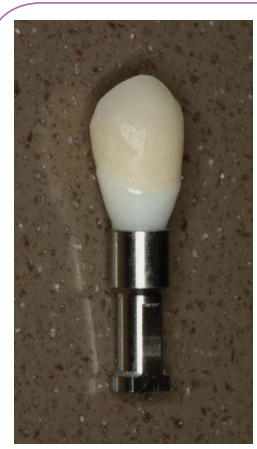

Figure 1n Immediate placement of 2 temporary crowns on Zirconium abutments.

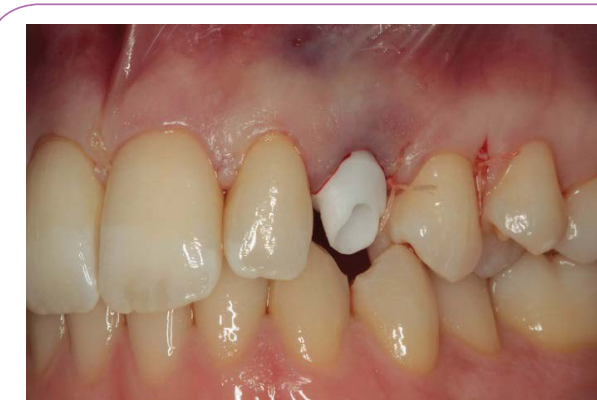

Figure 10 Immediate placement of 2 temporary crowns on zirconium abutments.

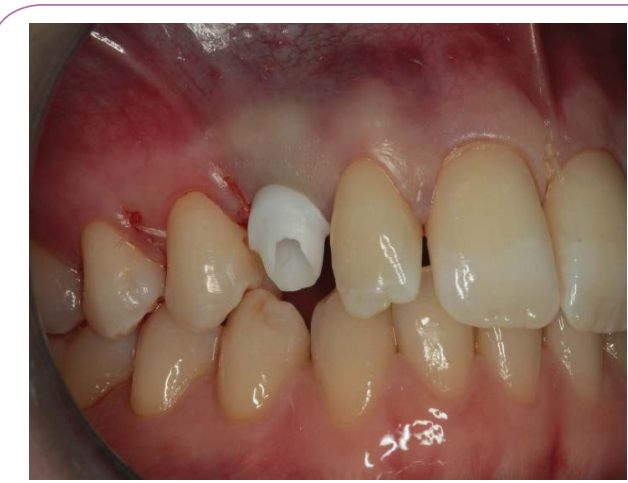

Figure 1p Immediate placement of 2 temporary crowns on zirconium abutments.

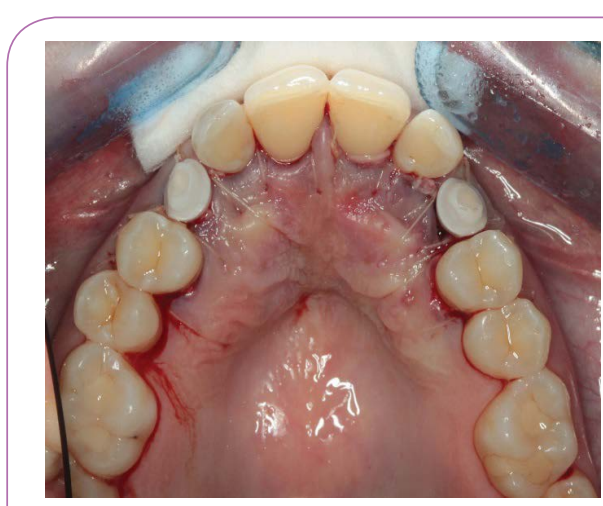

Figure 1q Immediate placement of 2 temporary crowns on zirconium abutments.

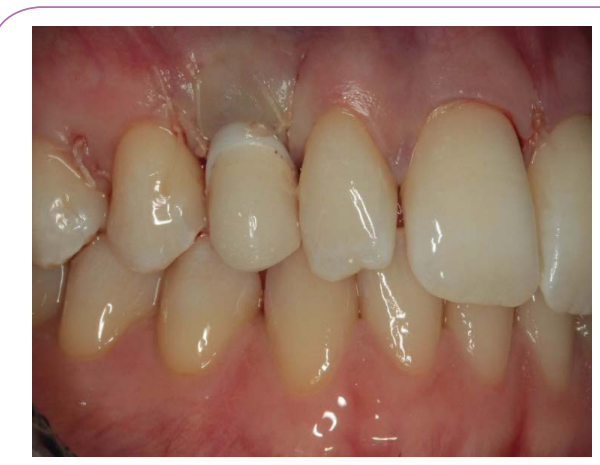

Figure 1r Immediate placement of 2 temporary crowns on zirconium abutments. 


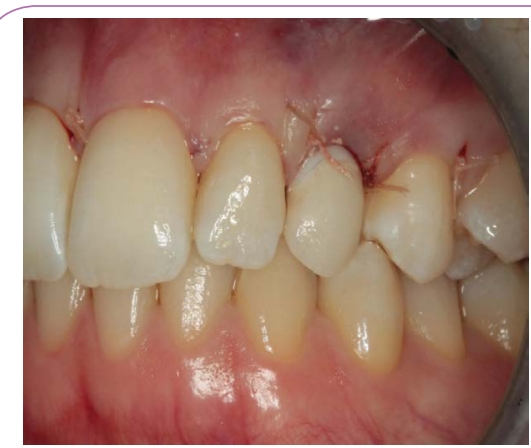

Figure 1s Immediate placement of 2 temporary crowns on zirconium abutments.

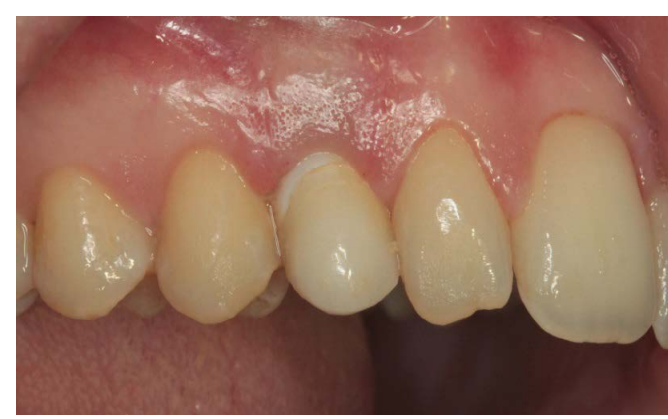

Figure 1t Clinical appearance on day-8 postoperative.

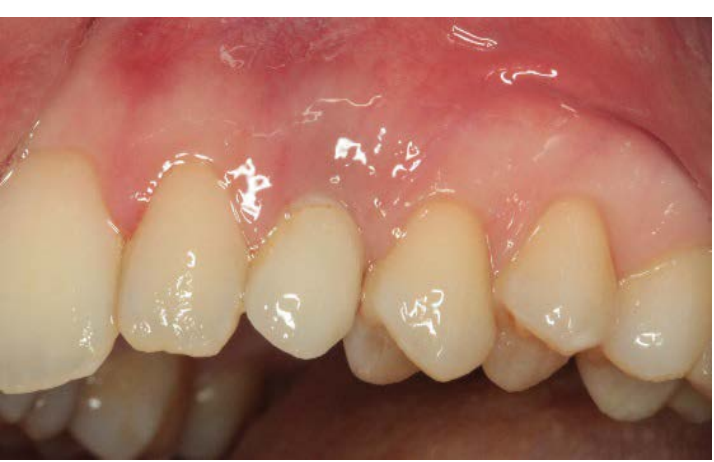

Figure 1u Clinical appearance on day-8 postoperative.

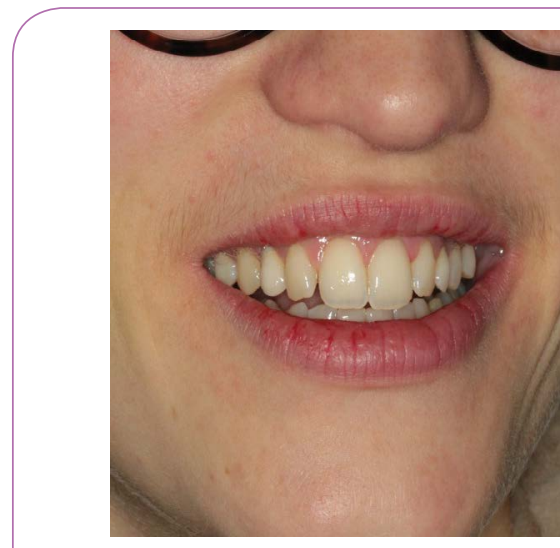

Figure 1v Clinical appearance on day-8 postoperative.
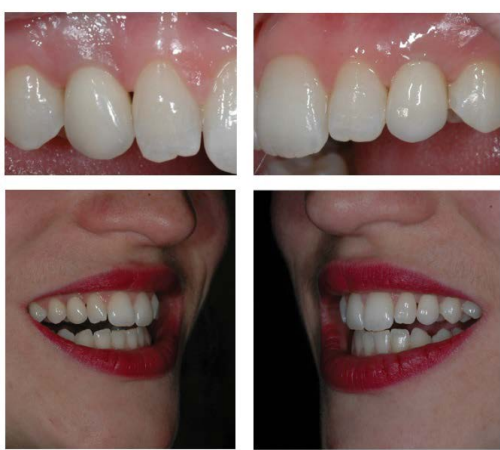

Figure 1w Final prosthetic crowns after a period of 4 monthshealing (Dr. DELESTI/Lab. CERALOR).

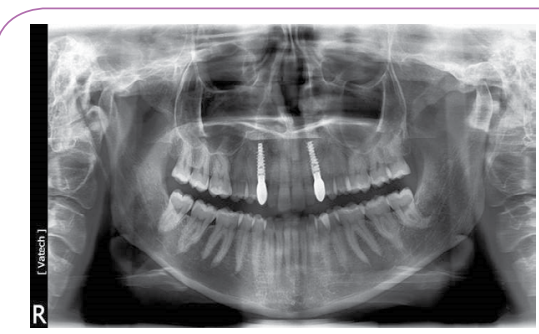

Figure 1x Final prosthetic crowns after a period of 4 monthshealing (Dr. DELESTI/Lab. CERALOR). 
Case 2: February, 2014: young woman, 38 years old, presenting an internal resorption on her upper right canine. Her general practitioner cannot treat and save it. The demand consists I an immediate tooth replacement with respect of esthetic clinical appearance (Figures $\mathbf{2 a - 2 g}$ ).

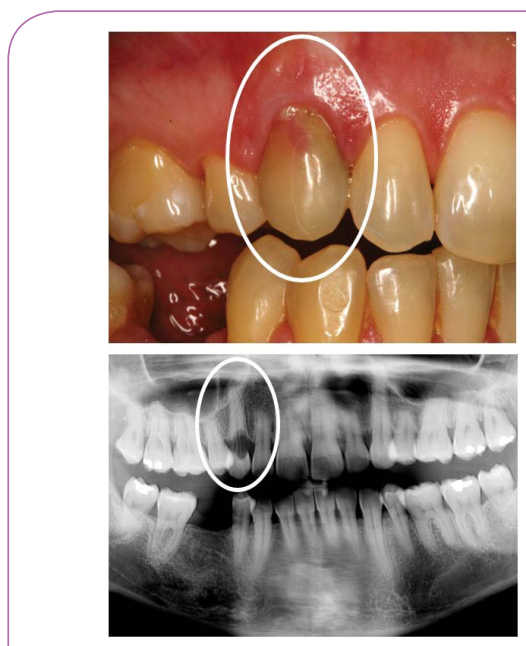

Figure 2a Initial clinical and radiological presentation.

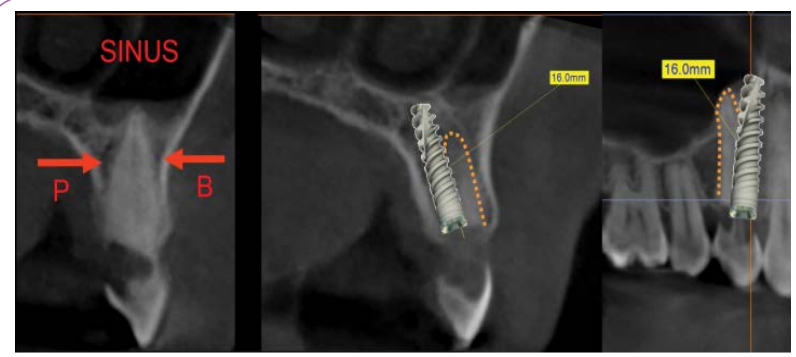

Figure 2b 3D R-Ray analysis and treatment plan: after tooth extraction, we'll try to insert the implant according to a double lead angle axis in order to get an initial primary fixation of the implant, while also taking care not to touch the sinus cavity and the proximal vital roots as well.
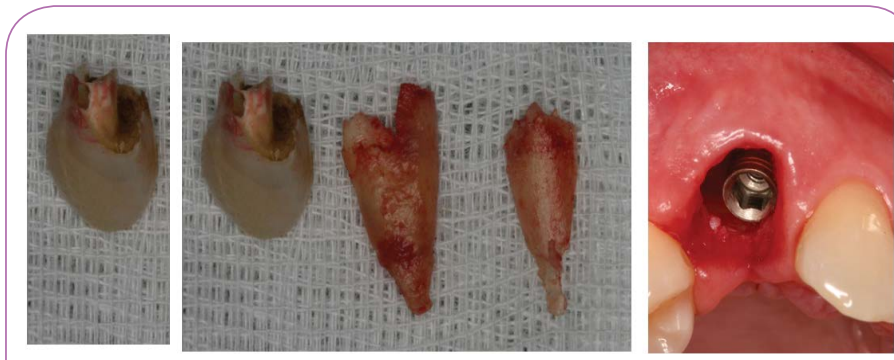

Figure 2c

Tooth extraction and immediate implant (AlphaBio Tec SPI) placement.
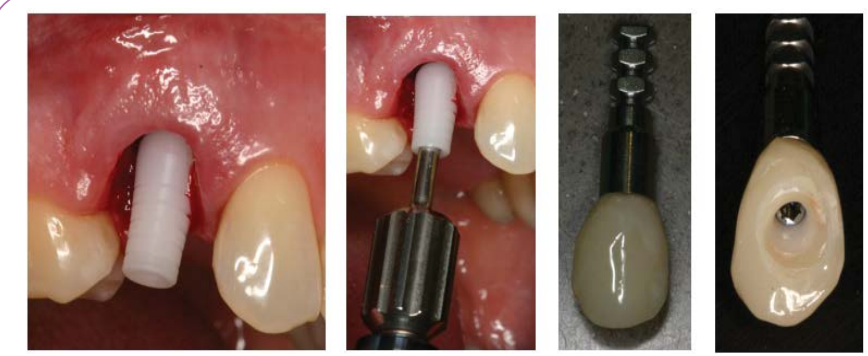

Figure 2d

The whole surgical-temporary-prosthetic protocol is achieved so that we can place a screwed-in (palatal access) temporary crown immediately after surgery.
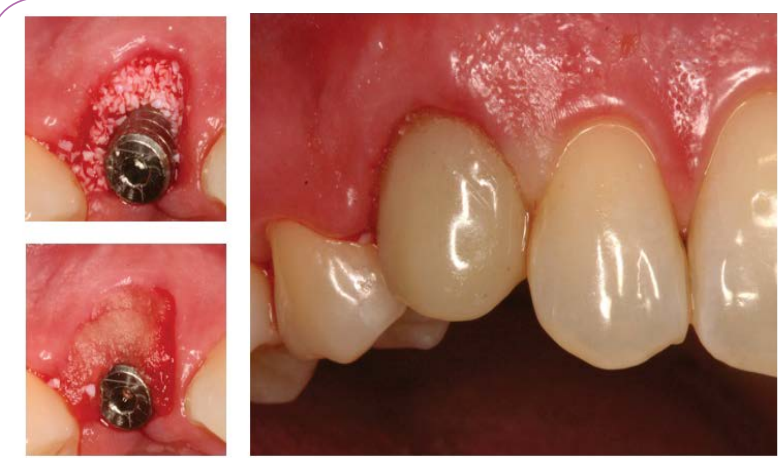

Figure 2e

Bio-Oss bone filling around the implant body, just before temporary crown placement (by direct screwing / no cement).
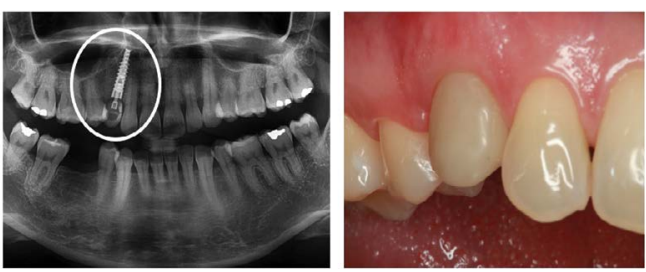

Figure $\mathbf{2 f}$ Clinical and radiological result at 8 days postoperative.
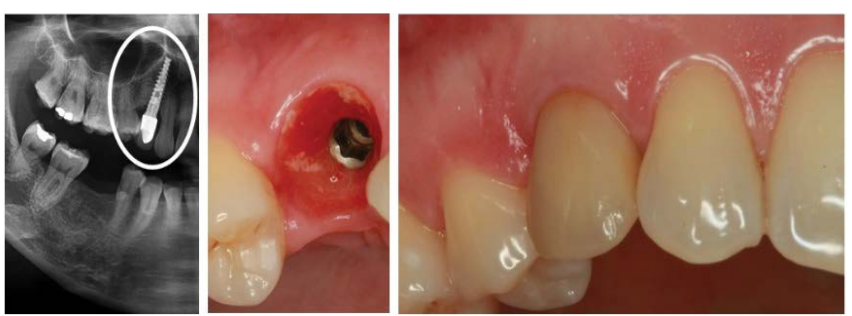

Figure $2 \mathrm{~g}$ Last clinical check, final crown in place (Dr. CHAPELLE) and X-Ray control at 4 months postoperative. 


\section{Part II: Immediate Implant Placements for Full-Arch Fixed Reconstructions}

As practitioners, we frequently must choose between "treat and conserve" or "pull out and replace" [37]. It is frequently technically possible to rebuild ad integrum full dental arches in patients who require this (Case 3 ). The negative side is that these types of treatments are often long and need a lasting cooperation between the patient and the mouth-care team. I visited Paulo Malo in Portugal a year after he published his work in 2005 [38]. Dr. Malo suggests treating edentulous patients in a simplified manner, even in the case of atrophic maxillae showing prominent sinus cavities. After returning to France, I began using his method and it has basically changed part of my implant practice.

But the most important change to my treatment practices came about in 2010 when a patient (an architect, 49 years old, sent by his general practitioner) came for another implant treatment after I had already placed 2 implants in his lower left jaw in 2006. His original demand was new but very clear:

"I've got lots of problems in my mouth already, including teeth which have been treated with or without crowns and I'm fed-up with wasting so much time and money at the dentist's office. As an architect, I can understand that it is easier to construct a new building on clean, virgin land than it is to conserve some of the original parts of the old building while building a new one. Is this approach acceptable to you as a dentist?"

Indeed, as a practitioner, I could understand his point of view, although I tried to convince him to conserve and treat his natural teeth to the extent that it was possible. But he insisted on a "Robocop Treatment".

Besides the questionability of extracting curable and/or healthy natural teeth in order to put in an implant supported restoration, we must say that:

- This personalized approach is easy to understand $[39,40]$;

- Experience confirms that this approach is technically and clinically feasible to do all at one time;

- Such a radical approach could actually lead to fewer postoperative complications and to a better final prognosis than a more traditional, conservative treatments [41].

We finally accepted the terms of the treatment... (Case 4)

Today we feel secure in such implant treatments for the following reasons:

- Patient satisfaction can be higher with this method than with more difficult, time-consuming, traditional treatments (Case 5);

- Patients feel better immediately;
- Patients with this type of treatment take better care of their new teeth (Case 6);

- The long term prognosis may be better.

\section{Case 3}

August, 2006: man, 49 years old motivated by changing his esthetic aspects (Figures 3a-3e).
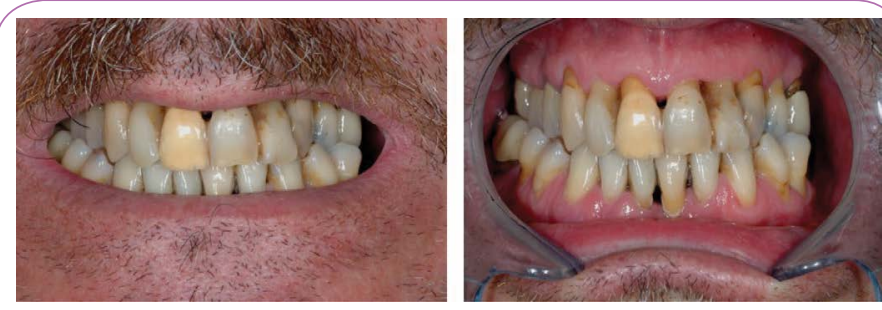

Figure 3a Initial clinical esthetic appearance.
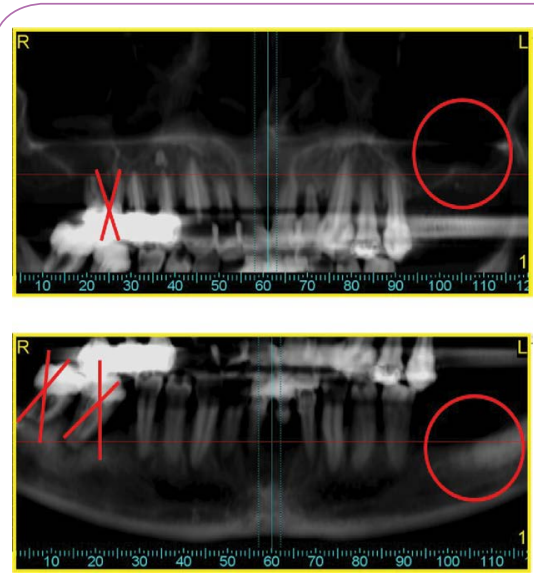

Figure 3b Radiological investigation shows lack of occlusal stabilization on both posterior areas, forcing the patient to chew on the (mobile) front teeth.
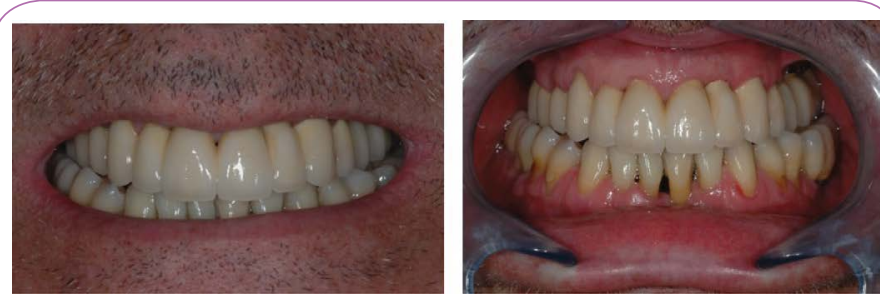

Figure 3c Final esthetic and stable result after conservative and replacing treatments (final prosthesis by Dr. DELESTI / Lab. CERALOR). 


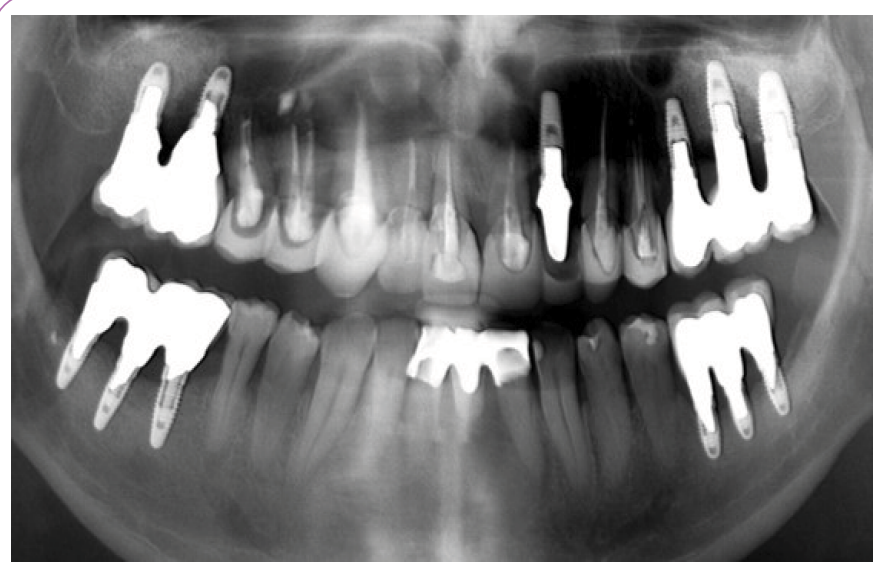

Figure 3d FinalX-Ray control showing results of conservative (endoperio-prosthétic) treatments on front teeth (excepted for left lateral incisor) and replacing treatments (bone grafts and implants) on the posterior areas.

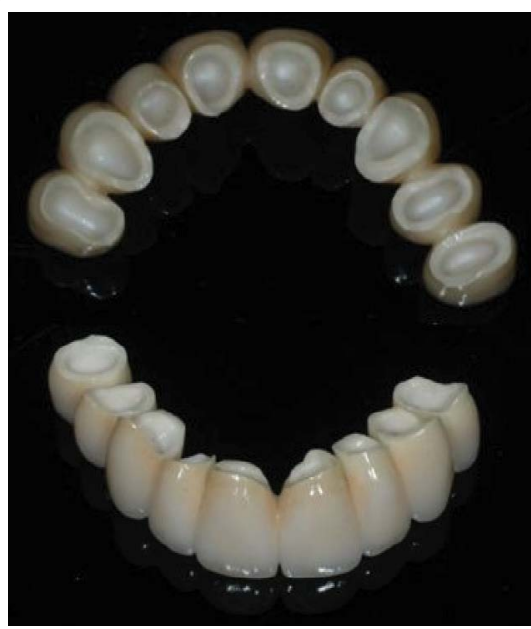

Figure 3e Here, we assumed [42,43] a rigid implant-teeth connection (zirconium-ceramic crowns) allowing a good esthetic and biomechanical result with a good long-term prognosis as well.

\section{Case 4}

October, 2010: man, 51 years old demanding a "ROBOCOP" treatment (Figures 4a-4c).

\section{Case 5}

February, 2014: woman, 51 years old with apertognathia, demanding an efficient-esthetic treatment. The whole treatment
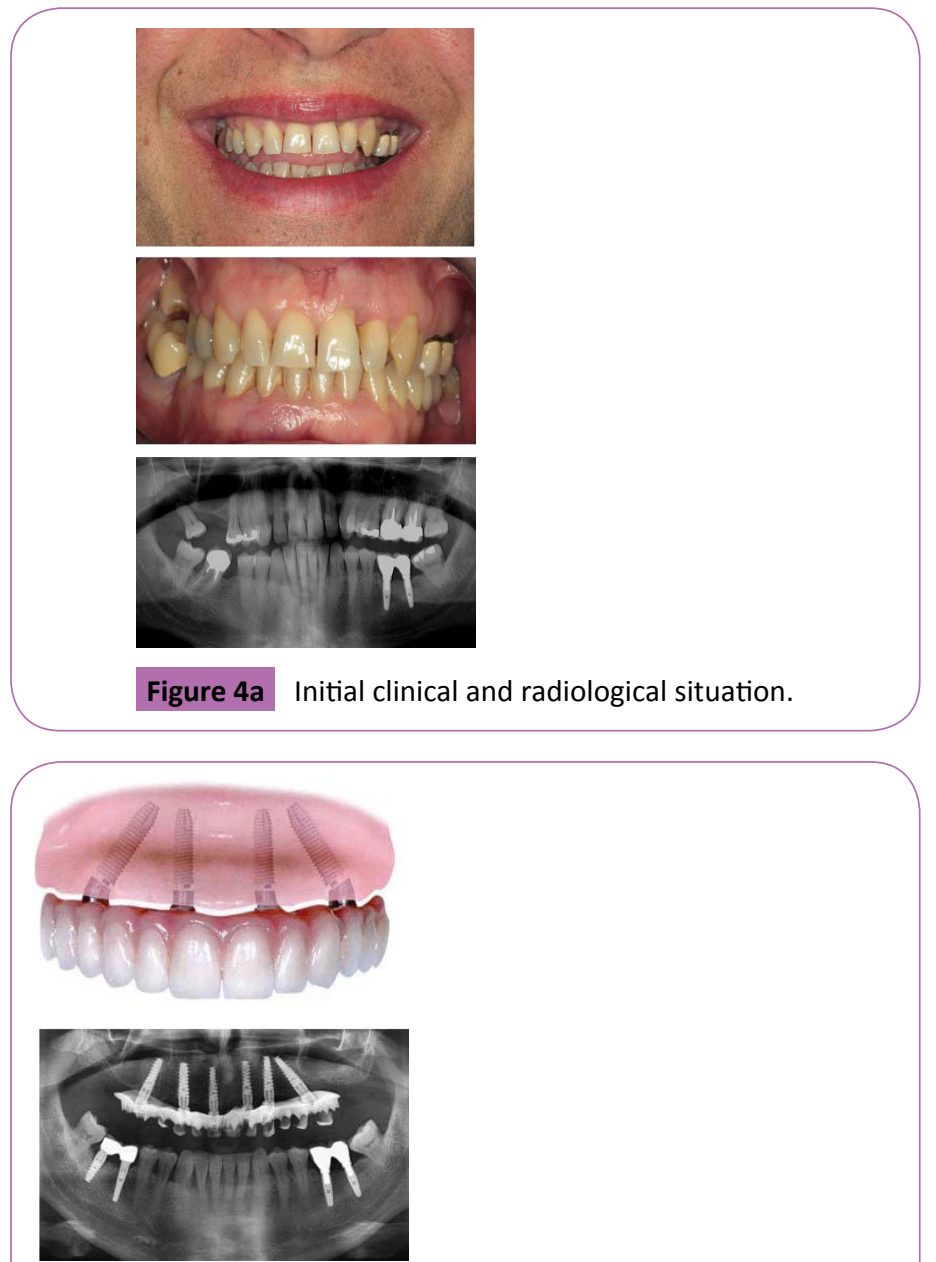

Figure 4b Final result, 4 months after the unique surgical phase (teeth extraction+immediate implant placements+immediate temporary fixed full-arch denture).

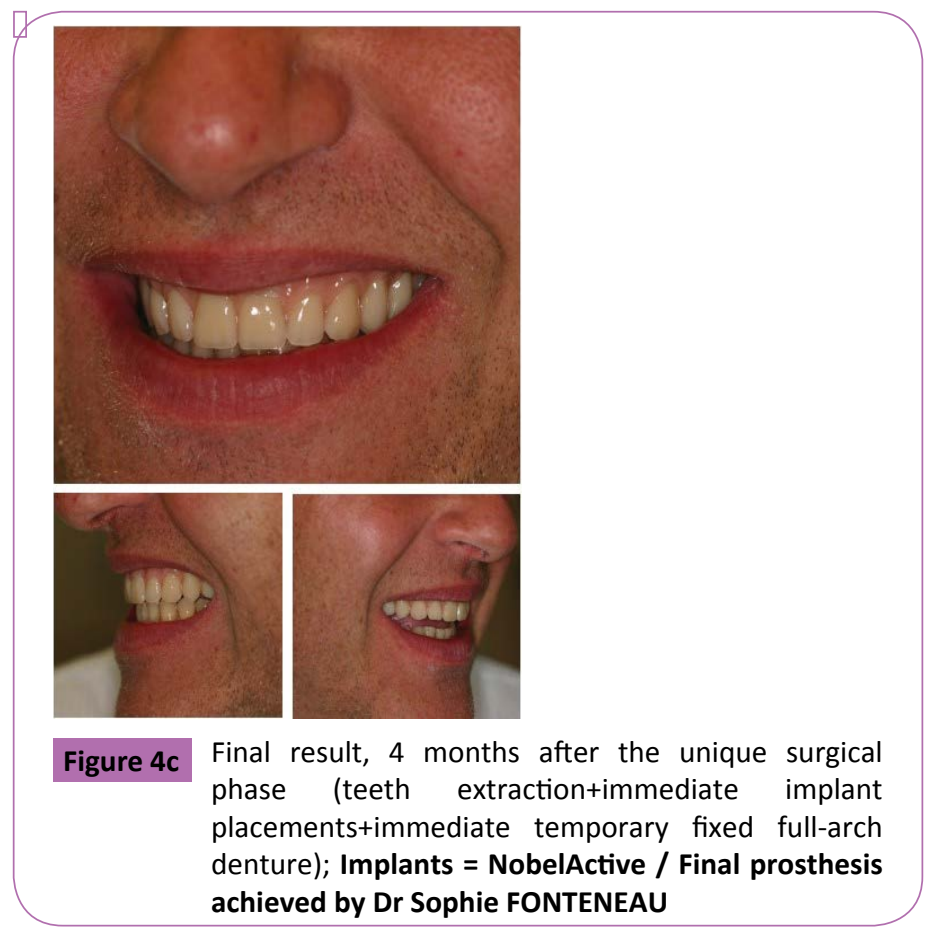


was achieved with 2-step surgery (one for the upper jaw and one for the lower jaw), under local anesthesia, with immediate full denture placement for waiting the implants osseointegration. Both final dentures are made of ceramic-zirconium (Figures 5a5i).

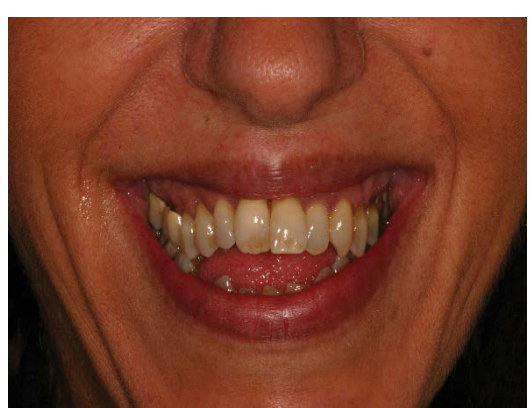

Figure 5a Initial clinical presentation / occlusion.

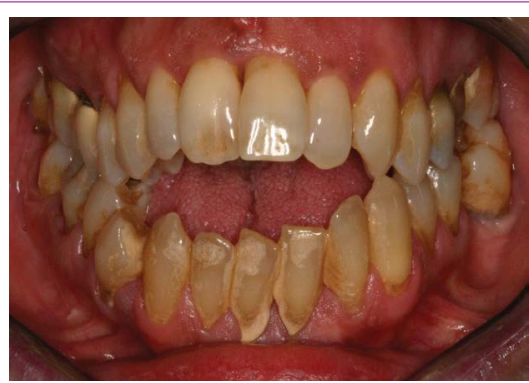

Figure 5b Initial clinical presentation / occlusion.

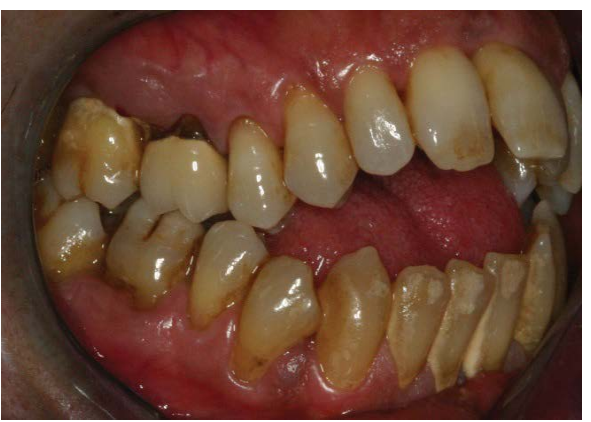

Figure 5c Initial clinical presentation / occlusion

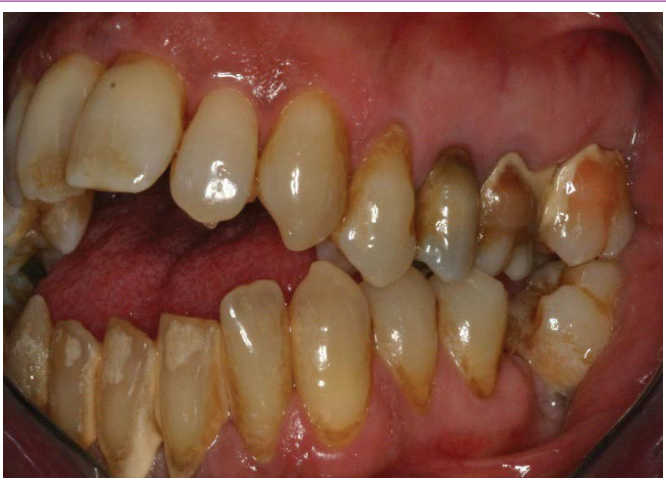

Figure 5d Initial clinical presentation / occlusion.
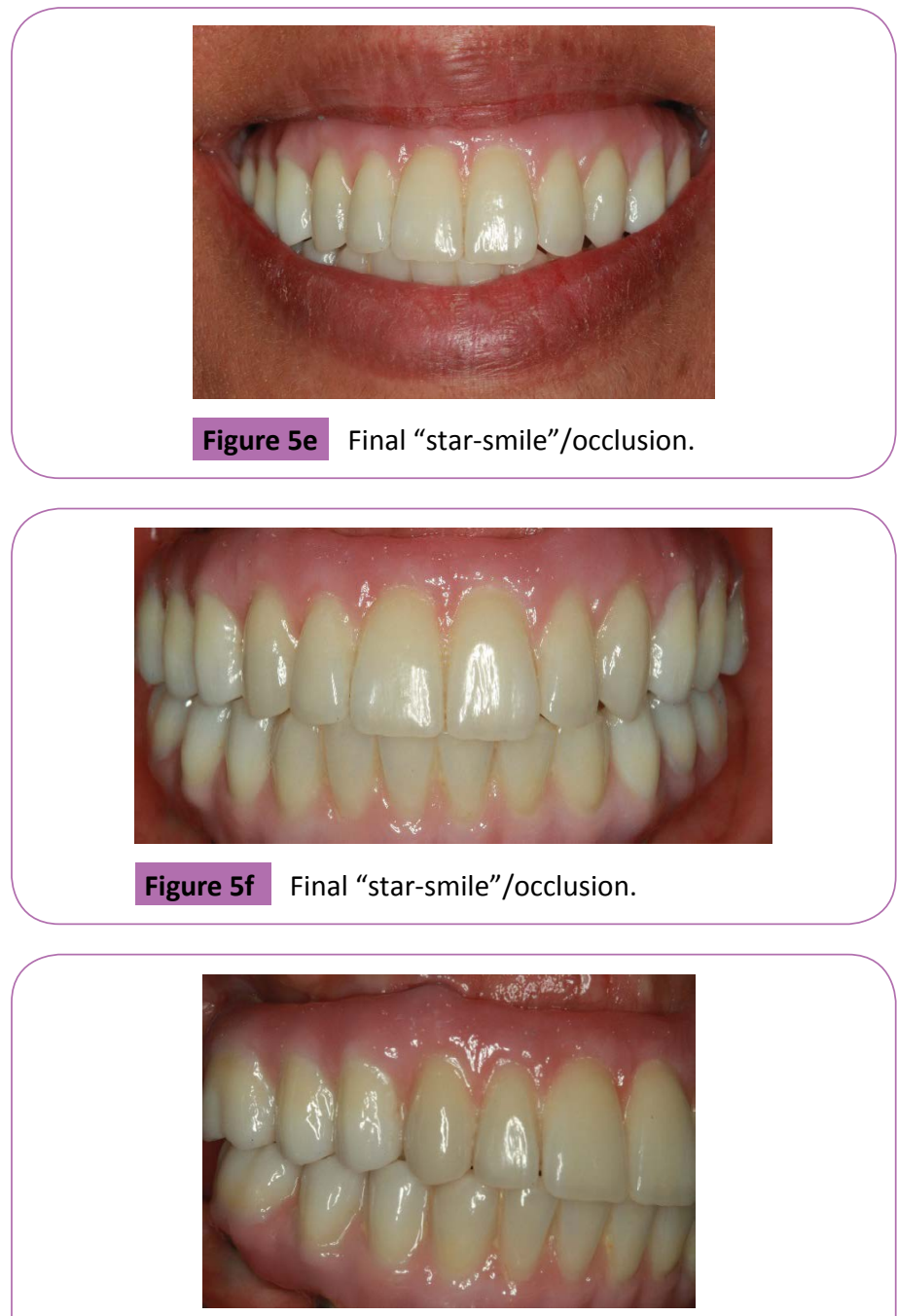

Figure 5g Final "star-smile"/occlusion.

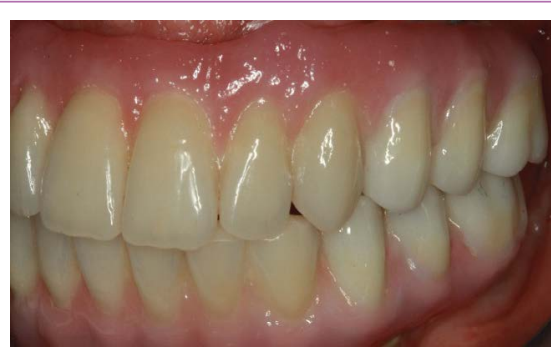

Figure 5 h Final "star-smile"/occlusion.

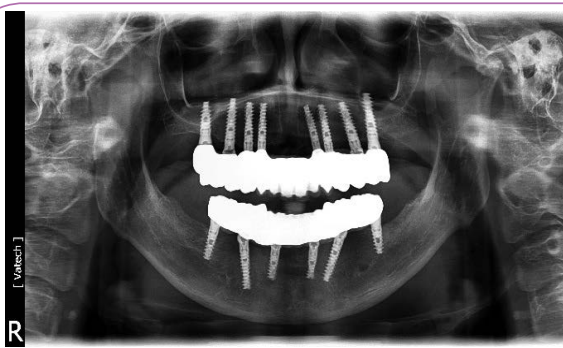

Figure 5i Final X-Ray (February, 2015) control showing the 8 implant (AlphaBio Tec)-supported denture on the maxilla and the 6 implant (AlphaBio Tec SPI)-supported denture on the mandible (Lab. = Erick LOYAU). 


\section{Case 6}

June, 2015: young man (pastry cook), 31 years old demanding a "ROBOCOP" treatment... But nothing else (he is a friend of the man/ case 4). He clearly shows no motivation for a conservative treatment. The patient is also taught to special hygiene practice and occlusion protection night-wearing as well (Figures 6a-6j).
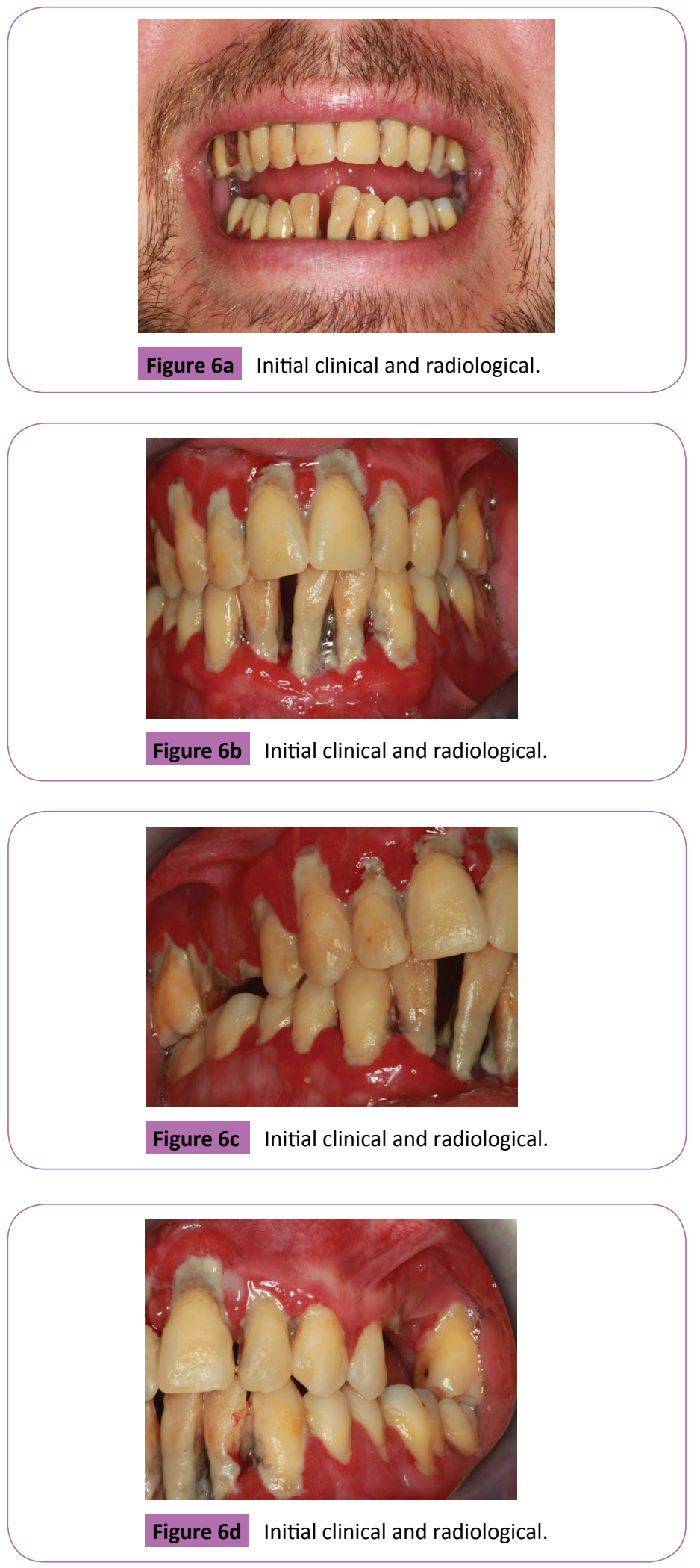
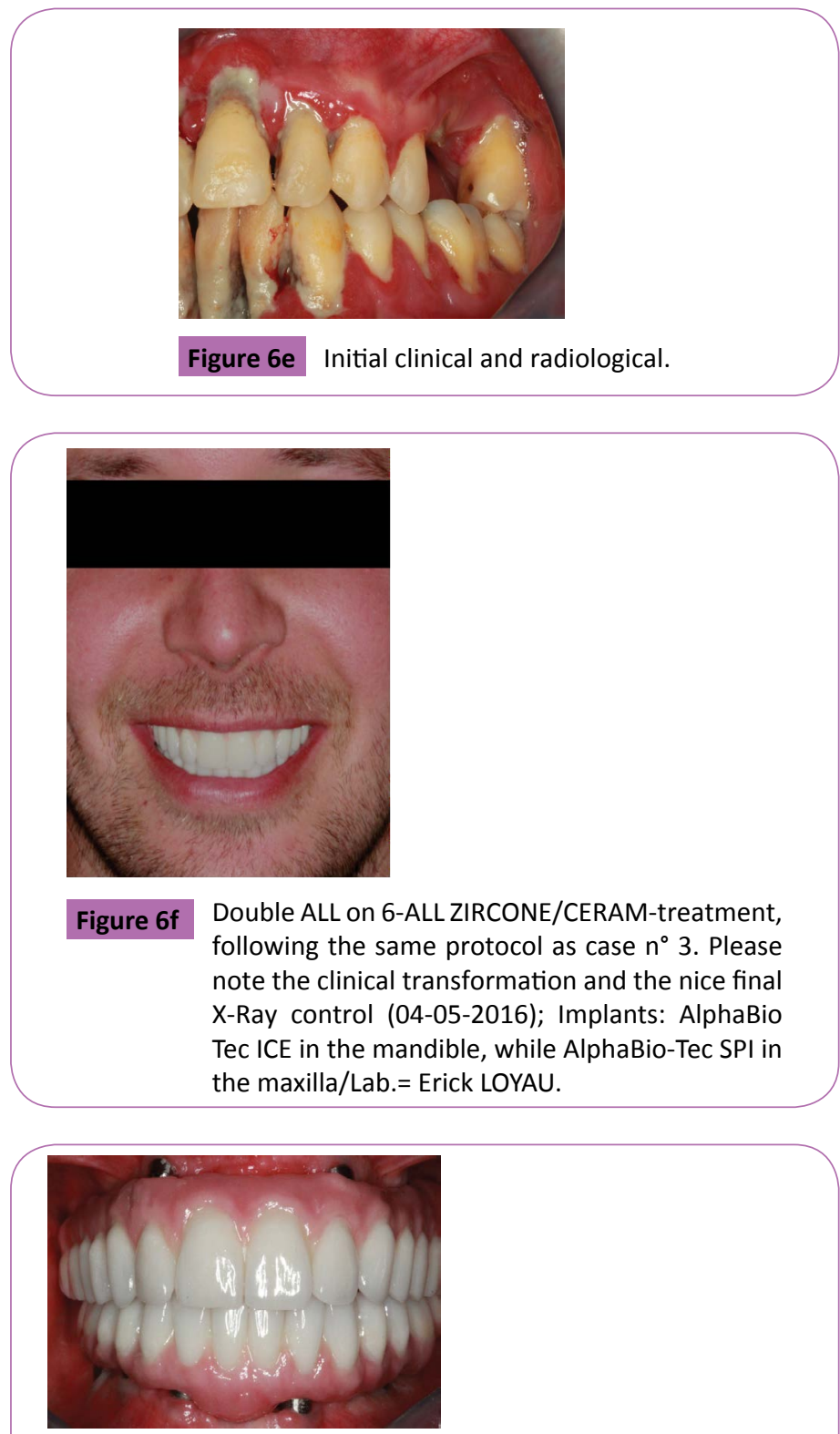

Figure $6 \mathrm{~g}$ Double ALL on 6-ALL ZIRCONE/CERAM-treatment, following the same protocol as case $n^{\circ} 3$. Please note the clinical transformation and the nice final X-Ray control (04-05-2016); Implants: AlphaBio Tec ICE in the mandible, while AlphaBio-Tec SPI in the maxilla/ Lab.= Erick LOYAU.

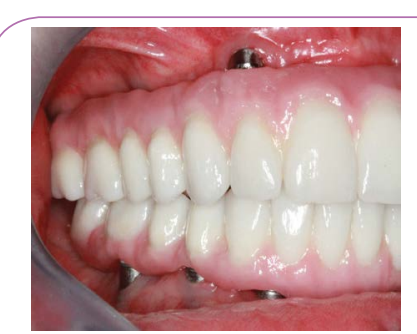

Figure 6h Double ALL on 6-ALL ZIRCONE/CERAM-treatment, following the same protocol as case $n^{\circ} 3$. Please note the clinical transformation and the nice final X-Ray control (04-05-2016); Implants: AlphaBio Tec ICE in the mandible, while AlphaBio-Tec SPI in the maxilla/ Lab.= Erick LOYAU 


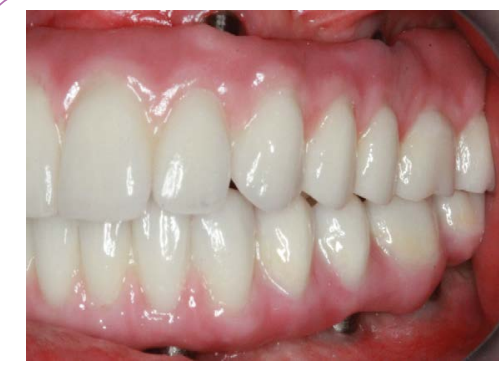

Figure 6i Double ALL on 6-ALL ZIRCONE/CERAM-treatment, following the same protocol as case $n^{\circ} 3$. Please note the clinical transformation and the nice final X-Ray control (04-05-2016); Implants: AlphaBio Tec ICE in the mandible, while AlphaBio-Tec SPI in the maxilla/ Lab.= Erick LOYAU.

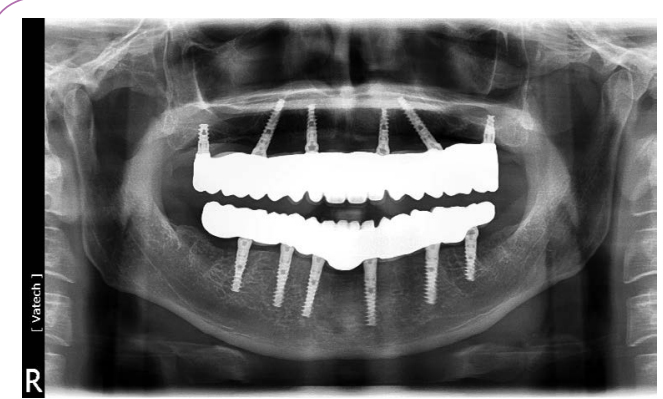

Figure 6j Double ALL on 6-ALL ZIRCONE/CERAM-treatment, following the same protocol as case $n^{\circ} 3$. Please note the clinical transformation and the nice final X-Ray control (04-05-2016); Implants: AlphaBio Tec ICE in the mandible, while AlphaBio-Tec SPI in the maxilla/Lab.= Erick LOYAU.

\section{Conclusion}

Through continuing education, the practitioner can stay abreast of the latest developments including the most modern equipment and technologies, both of which lead to more efficient treatment and better patient satisfaction. Much can also be learned from listening to our patients as reported in various clinical experiences in this paper. 


\section{References}

1 Branemark PI, Zarb GA, Albrektsson T (1985) Tissue-Integrated Prostheses: osseointegration in Clinical Dentistry. Quintessence Publishing Co., Chicago, USA.

2 Safar P, Touboul C (2009) L'histoire clinique, hommage à J-C HARTER "Pourquoi j'ai jeté mon iconographie clinique aux oubliettes". JSOP, pp: 26-27.

3 Abbou M, Missika P (1993) Reprise de traitement implantaire: à propos d'un cas de fracture d'implants en céramique. Info Dent 19: 1399-1408.

4 Abbou M, Missika P (1994) Extractions-implantations immédiates et membranes Gore-Tex ${ }^{\circledR}$. Considérations cliniques et techniques. Chir Dent 700: 23-28.

5 Abbou M, Missika P (1997) Extractions-implantations immédiates. Rev Stomatol Chir Maxillo-fac 98: 14-16.

6 Missika P, Abbou M, Rahal B (1997) Osseous regeneration in postextraction implant placement: A literature review and clinical evaluation. Pract Periodont Aesthetic Dent 9: 165-175.

7 Barzilay I, Graser G, Iranpour B, Caton J, Schenkle G (1988) Immediate implantation of pure titanium threated implants into extraction sockets. Int Dent Res 67: 142.

8 Lazzara R (1989) Immediate implant placement into extraction sites: surgical and restorative advantages. Int J Periodont Rest Dent 9: 333-343.

9 Amoyel F, Itic J (2000) L'implantation immédiate après extraction. Information dentaire 25: 1897-1908.

10 Schwartz-Arad D, Chaushu G (1997) Placement of implants into fresh extraction sites: 4 to 7 years retrospective evaluation of 95 immediate implants. J Peridontol 68: 1110-1116.

11 Grunder U, Polizzi G, Goene R, Hatano N, Henry P, et al. (1999) A 3 -year prospective multicenter follow-up report on the immediate and delayed-immediate placement of implants. Int J Oral Maxillofac Implants 14: 210-216.

12 Waasdorp JA, Evian Cl, Mandrachia M (2010) Immediate placement of implants into infected sites: A systematic review of the literature. J Periodontol 81: 801-808.

13 Buser D, Weber HP, Lang NP (1990) 1-year results of a prospective study with 100 ITI hollow-cylinder and hollow-screw implants. Clin Oral Impl Res 1: 33-40.

14 Collaert B, De Bruyn H (1998) Comparison of Bränemark fixture integration and short-term survival using one-stage or two-stage surgery in completely and partially edentulous mandibles. Clin Oral Impl Res 9: 131-135.

15 Ericsson I, Randow K, Nilner K, Petersson A (1997) Some clinical and radiographically features of submerged and nonsubmerged titanium implants. A 5-year follow-up study. Clin Oral Impl Res 8: 422-426.

16 Lambrecht T, Filippi A, Künzel AR, Schiel HJ (2004) Long-term Evaluation of Submerged and Nonsubmerged ITI Solid-Screw Titanium Implants: A 10-year Life Table Analysis of 468 Implants. Int J Oral Maxillofac Implants 18: 826-834.

17 Whörle P (1998) Single tooth replacement in the aesthetic zone with immediate provisionalisation. Fourteen consecutively cases report. Pract Periodontics Aesthet Dent 10: 107-114.

18 Kan JYK, Rungcharasseaeng K (1998) Immediate placement and provisionalization of maxillary anterior single implants: A surgical and prosthetic rationale. Pract Periodontics Aesthet Dent 10: 107-114.
19 Ostman PO, Hellman M, Senerby L (2005) Direct implant loading in the edentulous maxilla using a bone density-adapted surgical protocol and primary implant stability criteria for inclusion. Clin Implant Dent Relat Res 7: S60-S69.

20 Malo P, Rangert B, Nobre M (2005) All-on-4 immediate-function concept with Brånemark System implants for completely edentulous maxillae: a 1-year retrospective clinical study. Clin Implant Dent Relat Res 7: S88-S94.

21 Holmgren EP, Seckinger RJ, Kilgren LM, Mante F (1998) Evaluating parameters of osseointegrated dental implants using finite element analysis- a two-dimensional comparative study examining the effects of implant diameter, implant shape, and load direction. J Oral Implantol 24: 80-88.

22 O'sullivan D, Sennerby L, Meredith N (2000) Measurements comparing the initial stability of five designs of dental implants: a human cadaver study. Clin Impl Dent Rel Res 2: 85-92.

23 Pierrisnard L, Augerau D, Barquins M (2000) Analyse comparative par la méthode des éléments finis des contraintes osseuses induites par des implants de géométries variées. 1ère partie: influence relative du diamètre et de la longueur des implants. Implant 6: 23-33.

24 Norton MR (2001) Marginal bone levels at single tooth implants with a conical fixture design. The influence of surface macro- and microstructure. Clin Oral Impl Res 12: 79-84.

25 Callan DP, Hahn J, Hebel K, Kwong-Hing A, Smiler D, et al. (2000) Retrospective multicenter study of an anodized, tapered, diminushing thread implant: success rate at exposure. Implant Dent 9: 329-333.

26 Abbou M (2003) Primary stability and osseointegration: preliminary clinical results with a tapered diminishing-tread implant. Pract Periodontics Aesthet Dent 15: 161-168.

27 Turkilmaz I, Glumphy EA (2008) Influence of bone density on implant stability parameters and implant success: a retrospective clinical study. BMC Oral Health 8: 6831-6838.

28 Karmon B, Kohen J, Lor A, Gratciany I, Laster Z, et al. (2007) A Retrospective Multi-Centre Study on the Spiral Implant. World Conf, Las Vegas, USA.

29 Irinakis T, Wiebe C (2009) Clinical Evaluation of the Nobelactive Implant System: a Case Series of 107 Consecutive placed Implants and a Review of the Implant Features. J Oral Implantology 35: 283-288.

30 Orentlicher G, Teich M (2010) The NobelActive Implant: Discussion and case presentations. Compendium 31

31 Delgado Ruiz A, Calvo Guirado JI, Mate Sanchez De Val JE, Gomez Moreno G, Javed F, et al. (2016) Primary stability of dental implants with different thread geometries placed by clinicians with different clinical experience: An in vitro study. Dent Tribune Science.

32 De Wijs Fl, Van Dongren RC, De Lange GI, De Puter C (1994) Front tooth replacement with Tubingen (Frialit) implants. J Oral Rehabilitation 21: 11-26.

33 Gomez-Roman G, Schulte W, D'hoedt B, Axman-Kremar D (1997) The Frialit-2 implant system: five-year clinical experience in single-tooth and immediately postextraction applications. Int J Oral Maxillofac Implants 12: 299-309.

34 Wöhrle PS (1997) The synergy of taper and diameter: enhancing the art and science of implant dentistry with the ReplaceTM implant system. Int J Dent Symp 4: 48-52.

35 Abbou M (1998) Pertes incisives au maxillaire: évaluations cliniques, information du patient et choix thérapeutiques. Alpha Omega News 38: 7-9. 
36 Abbou M (2015) L'incisive centrale en implantologie. Apport de l'imagerie 3D. Tribune Dentaire. French edn., Janvier, p: 30.

37 Abbou M, Bonner M, Caron G, Tordjmann N, Lasfargues JJ (2016) Faut-il traiter et conserver ou extraire et remplacer? Conference SICT mieux, Paris, France.

38 Malo P, Rangert B, Nobre M (2005) All-on-4 Immediate-Function Concept with Bränemark System Implants for Completely Edentulous Maxillae: A One-Year Retrospective Clinical Study. Clin Impl Dentistry and Rel Research 7: 588-594.

39 Abbou M, Abensur D, Missika P (1995) Techniques avancées en implantologie. Rev Odontostomatol 24: 165-178.

40 Abbou M (1998) Pertes incisives au maxillaire : évaluations cliniques, information du patient et choix thérapeutiques. Alpha Omega News 38: 7-9.

41 Eliaszewicz-Wajnsztok S, Tabernier B (2009) Analyse des taux de survie et complications des différentes solutions prothétiques : revue de littérature. Rev Odontostomatol 38: 187-207.

42 Abbou M, Chiche F, Picard B, Missika P (1995) Connexité prothétique entre implants et dents naturelles. Approche clinique, étude bibliographique et prospective. Les Cahiers de Proth 91: 57-68.

43 Genon P, Genon-Romagna C (1997) L'apport des implants dans le traitement des parodontites avancées. Comment les implants peuvent contribuer à améliorer le pronostic des dentures à parodonte réduit. J Parodontol Implantol Orale 16: 177-189. 